IJIET, e-ISSN 2548-8430, p-ISSN 2548-8422, Vol. 2, No. 2, July 2018

\title{
IJIET
}

International Journal of Indonesian Education and Teaching http://e-journal.usd.ac.id/index.php/IJIET

Sanata Dharma University, Yogyakarta, Indonesia

\section{MATHEMATICS CLASSROOM ACTIVITIES BASED ON SOME TOPICS IN GRAPH THEORY TO DEVELOP CRITICAL THINKING OF PRIMARY AND SECONDARY SCHOOL STUDENTS}

\author{
Eko Budi Santoso \\ Department of Mathematics Education, Sanata Dharma University \\ ekobudisantoso@usd.ac.id \\ https://doi.org/10.24071/ijiet.v2i2.921 \\ Received 12 January 2018; revised 26 May 2018; accepted 1 July 2018
}

\begin{abstract}
In Indonesia, graph theory is not part of Mathematics primary or secondary school Curriculum. Most students learn graph theory in university, especially those who takes major in Mathematics or Computer Science. This paper is a theoretical study in Mathematics Education which proposes some Mathematics classroom activities based on some concepts in graph theory to develop critical thinking for high school students as well as grade school. Some concepts in graph theory, such as vertex coloring and domination set can be used in primary and secondary schools to develop critical thinking of the students. These activities should be fun for the students since teacher may use it as a game in the class room.
\end{abstract}

Keywords: critical thinking, classroom activities, domination set, vertex coloring

\section{Introduction}

In Indonesia, graph theory is not part of grade school and high school curriculum (Depdiknas, 2016). In the United State of America, as part as her masteral research, Smithers (2005) discovered that a small amount of graph theory is taught as part as Discrete Mathematics with Statistics and Probability. But some high schools, according to Smithers, does not offer graph theory because they do not have enough manpower, or do not have enough time and rooms for an elective math course. Whether graph theory has been taught in school or not, still we can use some concepts in graph theory as classroom activities to improve their critical thinking capability. We do not need to spend too much time to teach graph theory to them, which will add some confusion to the students. It is possible, by giving some prior simple instruction for the activity, to ask the primary or secondary school student to do some activities based on some concept in graph theory without they know that they are solving a problem in graph theory. Thus, although, in Indonesia graph theory is not part of primary and secondary school curriculum, we may use some topics in graph theory, such as eulerian graph, spanning tree, vertex coloring, or domination, as a classroom activities to enhance critical thinking of the student. 
School is not a place for transferring knowledge only. Of course, such of transfer information is happening in school, but school should go further by developing other capabilities needed by the student in the future. Aside of reading, analyzing, leadership or social capabilities, critical thinking capability should also be developed in school, through various school activities, especially classroom activies.

According to the recent guideline from the department of education of Republic Indonesia (Depdiknas, 2016), one of a competence that should be achieved through Mathematics in classroom is a critical attitude through student's learning experience. This paper proposes some classroom activities based on sometopics in graph theory that can be used to achieve that objective, even though graph theory is not being taught in grade and middle school. The most important for the student is to practice how to think critically, using any information possible to solve the problem.

In this paper, we first discuss some ideas about critical thinking. Then we will review some basic concepts in graph theory needed in the classroom activity. The main discussion in this paper is some concrete classroom activity based on some concepts in graph theory, such as eulerian graph, spanning tree, vertex coloring, and domination.

Critical thinking is an important tool to solve daily life problems. Most of real life problems are complex and so it needs particular capability to solve it. To solve a problem, first we need to do a preliminary observation in order to get some information needed. Then, having some useful information, we need to choose a tool that can be used to solve the problem. Sometimes, we must go through several trial and errors to get a right tool to approach the problem. One of a capability needed for this kind of process is critical thinking.

In this paper, we use a definition of critical thinking stated by Florea and Hurjui (2015). They said that "Critical thinking is a way of approaching and solving problems based on arguments persuasive, logical and rational, which involves verifying, evaluating and choosing the right answer to a given task and reasoned rejection of other alternatives solutions." (Florea and Hurjui, 2015).Following the definition of critical thinking, Mathematics can be used to develop the critical thinking capability among the student. Of course, Mathematics is not the only subjects that can help students to foster their critical thinking capability. In Mathematics, the students are trained to solve problems using mathematical concepts they just learned.

Some researcher, such as Chukwuyenum (2013) and Dinuță (2015), studied the relation of critical thinking and mathematics in school. Chukwuyenum says that "critical thinking skills was also an effective means of enhancing students' understanding of Mathematics concepts." (Chukwuyenum, 2013). Furthermore, he recommends that an institution who trains secondary school Mathematics teachers should include critical thinking in their curriculum. This will improve students' performance in Mathematics. Dinuță studied the need of critical thinking to grasp geometric concepts among the students. She says, "The development of critical thinking is achieved through learning, a reason why the teacher must find 
didactic methods and means to highlight each learning experience of each geometric concept.” (Dinuţă, 2015).

When she took a class on Graph Theory and Its Application, Smithers (2005) learned that graph theory should be taught for high school student so they may be exposed earlier to the beauty of this branch of Mathematics. She then proposed some topics in graph theory that can be taught to secondary school students.

\section{Theory}

\section{Graph Theory}

In this section, we will review some basic concepts in graph theory. The beginning of the graph theory can be traced back to the eighteenth century, when Euler $(1707-1782)$, the father of graph theory, solved a famous problem called of Königsberg Bridge Problem (Harary, 1969:1). In Euler's time, the map of Königsberg city is shown in Fig. 1(a). We simplify the map and focus only to the river, lands, and bridges involved as shown in Fig. 1(b). Is it possible for us to begin at any of the four land areas, then we walk across each bridge exactly once and return to the starting point.

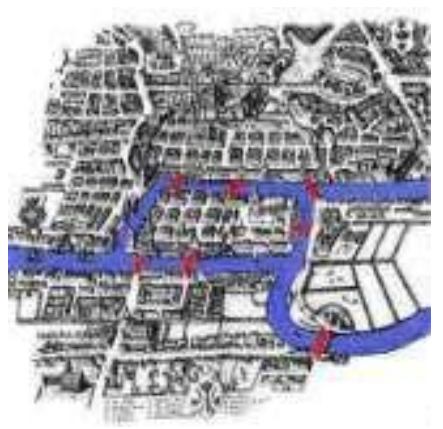

(a)

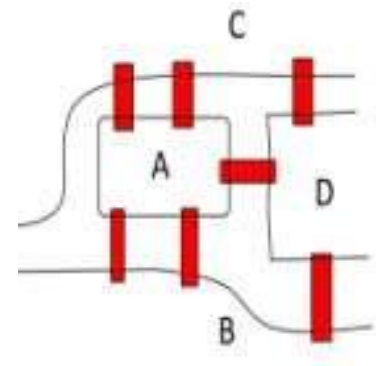

(b)

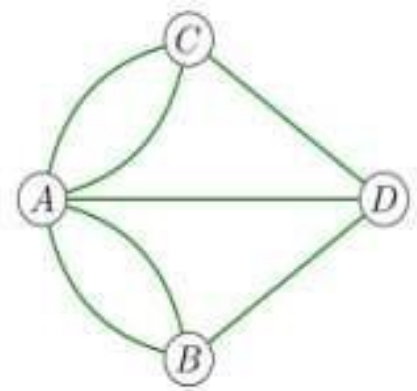

(c)

Figure 1. (a) A city map of Königsberg during Euler's time, (retrieved from http://www-history.mcs.st-andrews.ac.uk/Extras/Konigsberg.html), (b) its simplification, and (c) a graph that represents bridges connectivity in the city.

Euler showed that the problem is unsolvable. In his proof, he replaced each land area by a point and each bridge by a line joining the corresponding points. Thus we have a "graph" as shown in Fig. 1(c). Euler believes that the problem is geometric, but this kind of geometry is not the kind as known in his time which is geometry that involves measurements and calculations. He referred to a geometry which Leibniz said as Geometry of Position (Alexanderson, 2006).

A graph consists of a (finite) nonempty set of vertices (or nodes), and a set of edges. Each edge has either one or two vertices associated with it, called its endpoints. An edge is said to connect its endpoints. The number of vertices, the cardinality of is called the order of and is denoted by. The cardinality of is called the size of. A graph in which each edge connects two different vertices and where no two edges connect the same pair of vertices is called a simple graph. Two vertices and are called adjacent (or neighbors) in if and are endpoints of an edge of. Such an edge is called incident with the vertices and is said to connect 
and. In this paper, we only discuss connected undirected graph, which is a graph with undirected edge(s) and each vertex has a neighbor. The degree of a vertex is the number of edges incident with it. The degree of the vertex is denoted by. For other terminologies and concept not discussed in this paper, one may refer to Harary (1969) and Chartrand \& Lesniak (2004).

\section{Theory Application}

Before we discuss some topics in graph theory that can be used as a class activity, we first discuss some materials we may use in the classroom. Classroom activity based on graph theory does not need an expensive material. The activity only needs material for the students to draw small circles and lines. We may begin with materials are available in any classroom, which are black board and chalk, white board and marker, paper and pencil, or colored pencil and paper. As shown in Fig. 2(a), we draw small circles representing vertices and lines representing edges of a given graph. We can make our graph more attractive using a magnetic white board and colored magnet to represent vertices (Fig. 2(b)). If available, we can use small colored balls and sticks to represent vertices and edges as shown in Fig. 2(c). Basically, we may use anything that can represent vertices and edges.

In our activity, we do not have to explain explicitly concepts in graph theory. We just need to explain, using a simple language, the rule used in the activity. For most activities in this paper, the students are only required to know concept of neighborhood. The following are some concepts in graph theory that can be adopted as a class activity for grade or middle school students. For grade school students, we should choose a graph with only few vertices and edges.

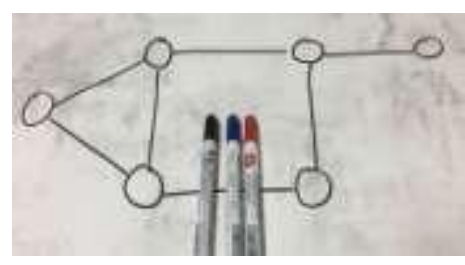

(a)

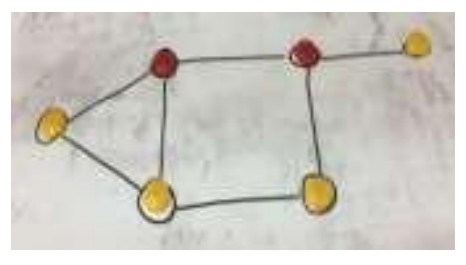

(b)

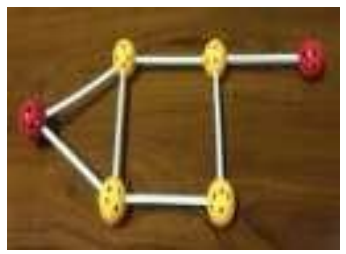

(c)

Figure 2. Some materials that can be used to represent a graph.

\section{Eulerian Graphs}

A walk of a graph is an alternating sequence of vertices and edges, beginning with vertex and ending with vertex, in which an edge connects the two vertices and for each. The number (the number of occurrences of edges) is called the length of. A walk is closed or open depending on whether or. A trailis a walk in which no edge is repeated. A graph is called eulerian if it has a closedeulerian trail, which is a walk that traverses each edge exactly once, goes through all vertices, and ends at the starting vertex. This concept adopts the Königsberg Bridge Problem which settled by Euler. Fig. 3(a) is an example of a eulerian graph. 


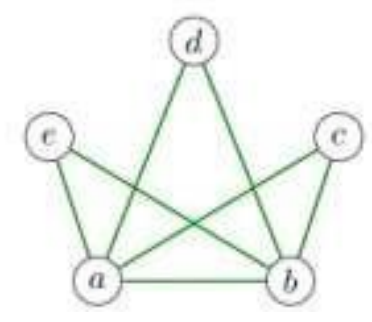

(a)

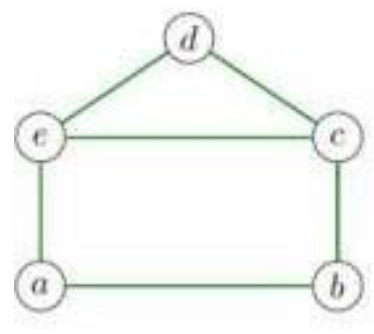

(b)

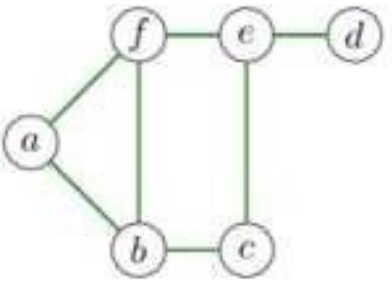

(c)

Figure 3. (a) A eulerian graph, (b) a graph contains a eulerian trail, and (c) a noneulerian graph.

We may use this concept in graph theory for a classroom activity. Given a graph, we ask the student to draw a similar graph without taking a pen from the paper and without retracing the same edge, begin and end at the same vertex. Ifthe student can do that, then a given graph is a eulerian graph. Different graphscan be given to the student during the activity. For high school students, we may ask the student to observe what property is needed so that a graph is eulerian.

We can modify our classroom activity to observe some graphs which are not eulerian, but they contain a eulerian open trail. In other words, we may draw a graph that contain a eulerian open trail without taking a pen from the paper and without retracing the same edge, but it does not require begin and end at the same vertex. Fig. 3(b) is an example of a graph that has a eulerian trail. If possible, we also may ask the student to observe what property of graph that contains a eulerian trail. Fig. 3(c) shows a graph which is both not a eulirean graph and does not contain eulerian open trail.

\section{Spanning tree}

An acyclic graph is a graph that has no closed trails. All graphs in Fig. 3 are cyclic because all of them has a closed trails. A tree is an acyclic connected graph. A spanning tree of a graph is a spanning subgraph of that is a tree.

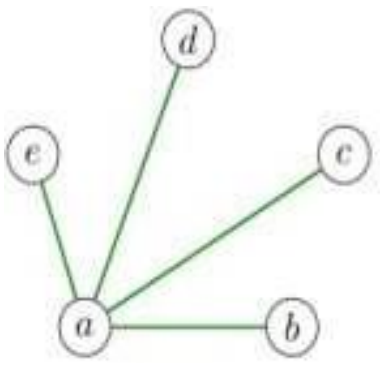

(a)

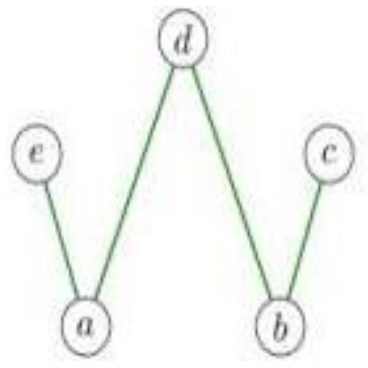

(b)

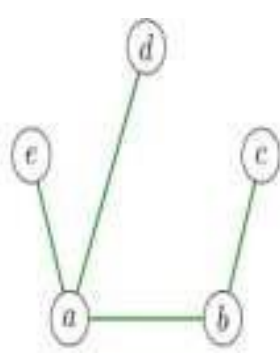

(c)

Figure 4. Three different spanning trees of a graph given in Fig. 3(a).

We first observe that for a given graph. It may have more than one different spanning trees. Fig. 4(a), Fig. 4(b), and Fig. 4(c) are three different spanning trees 
of the graph given in Fig. 3(a). Thus in our classroom activity, we may ask the student to observe all possible spanning trees for a given graph.

\section{Vertex Coloring}

A coloring of a graph is an assignment of colors to its vertices so that no two adjacent vertices have the same color (Harary, 1969: 126). An -coloring of a graph is a coloring of using colors. The chromatic number is defined as the minimum for which has an -coloring. The chromatic number for graphs shown in Fig. 5(a), Fig. 5(b), and Fig. 5(c) are, consecutively, 2, 3, and 5. In ourclassroom activity, we may ask student to find all possible coloring for a given graph. Then, for some advance student, we may ask chromatic number for a givengraph.

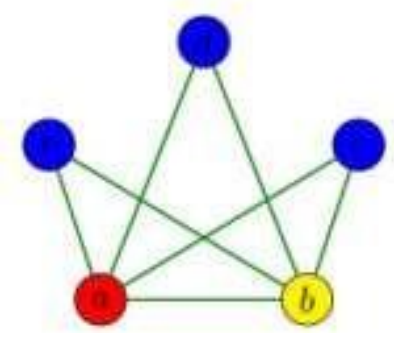

(a)

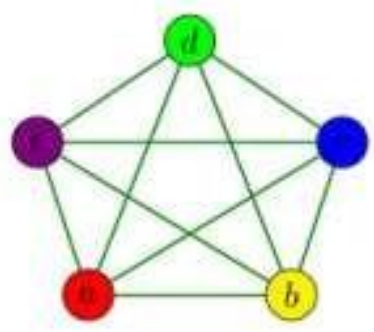

(b)

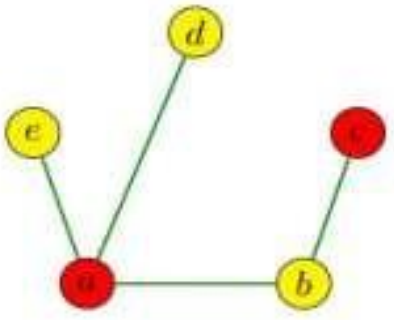

(c)

Figure 5. Three different graphs with their coloring.

\section{Domination}

The study of dominating sets in graph theory arose from a chessboard problem called the Five Queens Problem (Chartrand \& Lesniak, 2004: 274). In the 1850's, chess enthusiasts in Europe considered the problem of determining the minimum number of queens that can be placed on a chessboard so that all squares are either attacked by a queen or are occupied by a queen. It was correctly thoughtthat five is the minimum number of queens that can dominate all of the squares of a chessboard. One of possible configuration is shown in Fig. 6(a). This problem motivated the study of dominating set in graph theory, which was formalized mathematically by Berge in 1958 and Ore in 1962 (Chartrand \& Lesniak, 2004: 274).

A vertex in a graph is said to dominate itself and each of its neighbors that is each vertex adjacent to. A set of vertices of is a dominating set of if every vertex of is dominated by at least one vertex of. Equivalently, a set of vertices of is a dominating set if every vertex in is adjacent to at least one vertex in. As anexample, set and are dominating sets of graphs, respectively, shown in Fig. 6(b)and Fig. 6(c). The minimum cardinality among the dominating sets of is called the domination number of and is denoted by. As in previous activities, we may first ask student to find some dominating sets for a given graph, then for some advance student, we may ask them to find the domination number of the graph. 


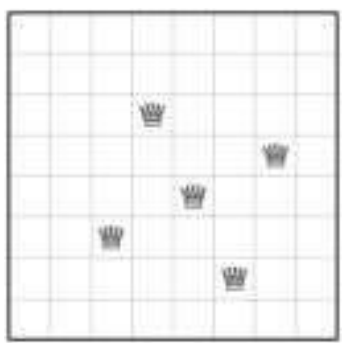

(a)

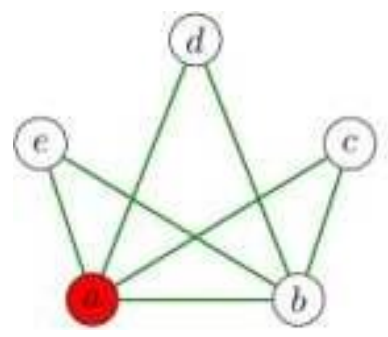

(b)

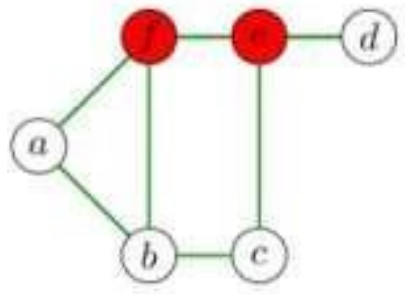

(c)

Figure 6. (a) A configuration of five queens on a $8 \times 8$ chessboard, (b) a graph with its domination number equals to one, and (c) a graph with its domination number equals to two.

\section{Conclusion}

This paper is a theoretical study that suggests classroom activities based on some concepts in graph theory. We believe that these activities will improve student's capability in critical thinking. Further experimental research is needed to know whether this classroom activity will help the student to improve their critical thinking.

\section{References}

Alexanderson, G.L. (2006). Euler and Konigsberg's bridges: A historical view. Bulletin of the American Mathematical Society, 43, 567-573.

Chartrand, G. \& Lesniak, L. (2004). Graphs \& digraphs Boca Raton, FL: Chapman \& Hall/CRC.

Chukwuyenum, A.N. (2013). Impact of Critical thinking on performance in mathematics among senior secondary school student in lagus state. IOSR Journal of Research \& Method in Education, 3(5), 18-25.

Depdiknas. (2016). Lampiran peraturan menteri pendidikan dan kebudayaan nomor 21 tahun 2016 tentang isi pendidikan dasar dan menengah. Jakarta: Departemen Pendidikan dan Kebudayaan Republik Indonesia.

Dinuță, N. (2015). The use of critical thinking in teaching geometric concepts in primary school. Procedia - Social and Behavioral Sciences, 180, 788 - 794.

Florea, N. M. \& Hurjui, E. (2015). Critical thinking in elementary school children. Proceida - Social and Behavioral Sciences, 180, 565 - 572.

Harary, F. (1969). Graph Theory. New York: Addison-Wesley Publishing Company, Inc.

Smithers, D. B. (2005). Graph Theory for the Secondary School Classroom (Electronic Theses and Dissertations). Retrieved from http:/dc.etsu.edu/etd/1015. 